\title{
Fabrication of graphene-ZnO heterostructure-based flexible and thin platform-based UV detector
}

\author{
Ashish Kumar ${ }^{1}$, Arathy Varghese ${ }^{2, *}$ (1), and Vijay Janyani ${ }^{3}$ \\ ${ }^{1}$ Department of Electronics Engineering, Banasthali Vidyapith, Tonk 304022, India \\ ${ }^{2}$ School of Engineering, Cardiff University, Cardiff CF24 3AA, UK \\ ${ }^{3}$ Department of Electronics and Communication, Malaviya National Institute of Technology, Jaipur 302017, India
}

Received: 29 August 2021

Accepted: 9 December 2021

Published online:

22 December 2021

(C) The Author(s) 2021

\begin{abstract}
This work presents the performance evaluation of Graphene/ZnO Schottky junctions grown on flexible indium tin oxide (ITO)-coated polyethylene terephthalate (PET) substrates. The fabricated structures include chemical vapour deposition grown graphene layer on ITO-coated PET substrates. Polymethyl methacrylate assisted transfer method has been employed for the successful transfer of graphene from $\mathrm{Cu}$ substrate to PET. The smaller D-band intensity $\left(1350 \mathrm{~cm}^{-1}\right)$ compared to G-band $\left(1580 \mathrm{~cm}^{-1}\right)$ indicates good quality of carbon lattice with less number of defects. High-quality $\mathrm{ZnO}$ has been deposited through RF sputtering. The deposited $\mathrm{ZnO}$ with grain size 50-95 nm exhibited dislocation densities of $1.31270 \times 10^{-3} \mathrm{~nm}^{-2}$ and compressive nature with negative strain of $-1.43156 \mathrm{GPa}$. Further, the electrical and optical characterization of the devices has been done through device $I-V$ characterization and UV detection analysis. The UV detection capability of the device has been carried out with the aid of a UV-lamp of $365 \mathrm{~nm}$ wavelength. The fabricated graphene/ $\mathrm{ZnO}$ photodetector showed good response to UV illumination. The device performance analysis has been done through a comparison of the device responsivity and detectivity with the existing detectors. The detectivity and responsivity of the fabricated detectors were $7.106 \times 10^{9} \mathrm{mHz}^{1 / 2} \mathrm{~W}^{-1}$ and 0.49 A $W^{-1}$, respectively.
\end{abstract}

\section{Introduction}

Recent decade has witnessed huge research focus on semiconductor-based UV detectors due to the high speed, low response times and ruggedness they provide for applications in harsh environment. Few exciting futuristic application domains include missile plume detection, monitoring the ozone layer, outer space communications, chemical and biological analysis etc. [1-3]. As the requirements and demand keeps on increasing, novel technologies with enhanced performances are replacing the basic

Address correspondence to E-mail: varghesea@cardiff.ac.uk 
detectors with features such as self-powering capability, flexibility, intelligence etc. [4-6]. To make feasible development of such futuristic detectors with minimal cost and process overheads, wide band gap rugged and transparent conducting oxides such as zinc oxide $(\mathrm{ZnO})$, tin oxide $\left(\mathrm{SnO}_{2}\right)$, indium oxide $\left(\mathrm{In}_{2} \mathrm{O}_{3}\right)$, indium tin oxide (ITO) etc. are considered while developing novel structures [7, 8]. Among these, $\mathrm{ZnO}$ becomes the prominent conducting oxide for UV detection application with its large exciton binding energy and ability to be doped without affecting its transparency $[9,10]$. $\mathrm{ZnO}$ nanostructures are modified with graphene junctions to overcome the limitations of poor resolution and low efficiency for photovoltaic applications. Another limitation of $\mathrm{ZnO}$-based devices is the poor absorption levels for incident light than the expected and theoretical calculations based on the $\mathrm{ZnO}$ bandgap. All these limitations can be mitigated by incorporating graphene into the device. Combination of graphene with these conducting oxides can give rise to an era of reliable devices in application domains such as sensors, lithium-ion batteries, supercapacitors, solar cells, and optoelectronics devices [11-14]. Graphene-modified $\mathrm{ZnO}$-based devices exhibit excellent efficiency in photovoltaic devices and give higher resolution in sensing applications. These advantages arise from the fascinating properties of graphene-like ultra-high transparency, conductivity, and mobility. Research focus in this direction is necessary as the graphene/ $\mathrm{ZnO}$ nanostructures provide better device performance by bringing in synergistic effects in electron transport as well as light absorption. Even though transistors are a compelling option towards development of UV detectors, they require complex fabrication processes and patterning for techniques to achieve required resolutions [15-17]. The advantage of using diode-based detector is that larger areas can be made available for UV detection, the sensitive area in a transistor-based sensor will be the channel or patterned gate which will have dimensions in the submicron range. This area in submicron range will be very small and limits the device sensitivity as the detector will be sensitive only to UV rays falling over this area. We focus on development of a simple diode-based detector through blanket deposition (without using hard or photoresist masks) of $\mathrm{ZnO}$ and graphene transfer. Diode-based sensors are chosen here from vantage points of lower cost, larger detection area, and minimal process overheads.
Deliverable through this work is a graphene/ $\mathrm{ZnO}$ heterojunction photodetector that can replace the existing $\mathrm{Si} / \mathrm{ZnO}$ heterojunction p-n detectors, Schottky detectors and MSM (Metal Semiconductor Metal) detectors. Optimum parameters and gas flow rates have been used in the sputtering-based deposition of $\mathrm{ZnO}$ nanolayers and chemical vapour deposition (CVD) growth of graphene nanosheets. Detailed discussion of the quality of deposition along with the deposition conditions is presented. The entire paper is organized as IV main sections where the II section discusses the processes, machines, methods, and parameters used in the fabrication of the graphene/ $\mathrm{ZnO}$ heterojunction. Subsequently, the next section demonstrates the quality analysis done for ensuring the quality of deposited layers where the surface morphological analysis and crystal orientations are investigated. This section also presents the electrical and UV detection characteristics of the device. Section IV presents the concluding remarks drawn based on the results and discussions and the comparative analysis presented in Section III.

\section{Experimental details}

This paper reports the performance analysis of a $\mathrm{ZnO} /$ graphene heterojunction UV detector grown on a flexible substrate. An intermediate structure grown to confirm the properties of the grown $\mathrm{ZnO}$ layer and the final device cross-sectional schematic is shown in Fig. $1 \mathrm{a}$ and $\mathrm{b}$ respectively. CVD based growth has been employed for graphene growth on copper foil due to its popularity and ease of transfer, low cost, and larger scale. Further, this growth mechanism also allows for the inclusion of foreign materials and dopant sources. During graphene synthesis, a hydrogen-rich environment is maintained and the precursors are introduced to the CVD chamber. Here, hydrogen acts as the catalyst in the formation of active surface bonds which is necessary for efficient graphene growth. Moreover, this can also etch away the weak carbon to carbon bonds formed. To grow high-quality $\mathrm{ZnO}$, RF sputtering technique has been used. It has been reported that compared to other growth methods such as thermal vapor deposition, pulsed vapor deposition, sol-gel process, etc. RF sputtering ensures quality deposition of uniform and smooth thin films [18]. Further, sputtering with its lower deposition costs and long-term stability stand 
(a)

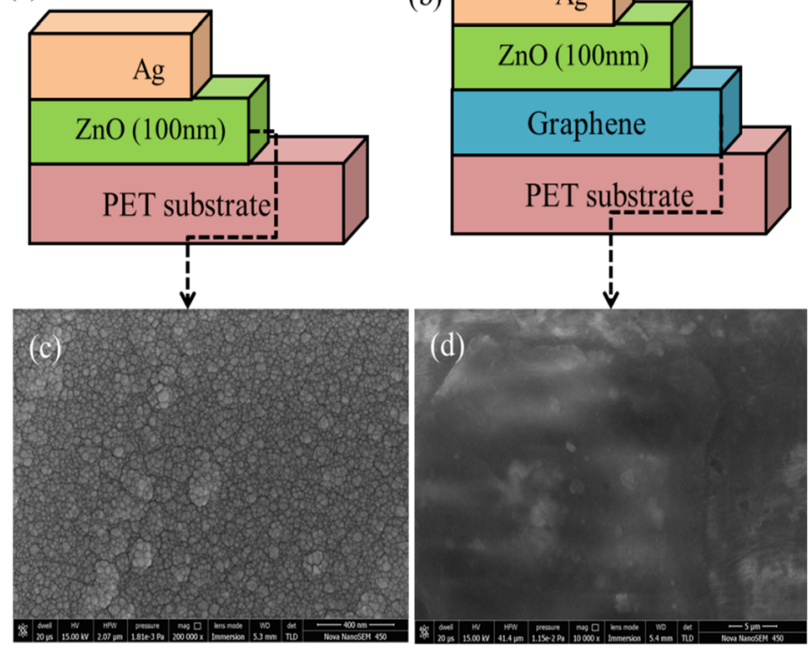

Fig. 1 a Conventional $\mathrm{ZnO} / \mathrm{Ag}$ ohmic junction on ITO-coated PET substrate, $\mathbf{b}$ Graphene/ZnO Schottky junction on ITO-coated PET substrate, $\mathbf{c}$ SEM image of RF-sputtered ZnO layer, $\mathbf{d}$ SEM image of CVD grown graphene layer

out as the choice for deposition of conductive oxides especially in diode fabrication with its potential advantages of low temperature deposition, good adhesion, and film uniformity [18-20]. The quality of the grown $\mathrm{ZnO}$ layer has been confirmed using XRD, AFM, EDX, and SEM analysis.

The graphene layer has been grown on $\mathrm{Cu}$ substrate and transfer to a flexible substrate through PMMA-assisted transfer method using APS as $\mathrm{Cu}$ etchant. The quality of the grown graphene layer has been ensured using Raman spectroscopy, SEM and AFM analysis. Further, the electrical characterization and comparison of results have been done using device $I-V$ characterization. The responses of the device towards UV light have also been tested and the performance enhancement of graphene-supported heterojunction UV detector has been validated. The graphene thin films have been grown on copper substrates with a thickness of $160 \mu \mathrm{m}$ using CVD. Prior to the deposition, the CVD chamber was calibrated and heated to a temperature of $1000{ }^{\circ} \mathrm{C}$ in Ar: $\mathrm{H}_{2}$ ambient with gas flow rates of $100 \mathrm{sccm}$ and 50 sccm respectively. During the deposition, methane gas was introduced to the chamber and a flow rate of $50 \mathrm{sccm}$ was maintained. Post deposition cooling was done in Ar: $\mathrm{H}_{2}$ ambient and the gas flow was maintained throughout the cooling process. The deposition was carried out maintaining a temperature of
$1000{ }^{\circ} \mathrm{C}$ in the CVD chamber using $\mathrm{Ar}$ and $\mathrm{H}_{2}$ as the driver gases and using methane as a precursor. The deposition parameters for CVD deposition of graphene are summarized in Table 1.

The graphene deposited $\mathrm{Cu}$ samples were then coated with a protective layer of PMMA using a spin coating technique. For the transfer of graphene flexible PET substrates, the samples were introduced to 0.1 M APS (Ammonium Persulphate: Sigma Aldrich, purity: $98 \%$ ) for etching of $\mathrm{Cu}$ substrate. The delaminated graphene layer (as shown in Fig. 4) with PMMA was then fished in deionized water onto the surface of an ITO coated PET substrates. The samples were then heated at $70{ }^{\circ} \mathrm{C}$ for $20 \mathrm{~min}$ to ensure the adhesion of graphene onto the substrate after removal of PMMA using acetone. $\mathrm{ZnO}$ thin layers were then deposited using RF sputtering. A $\mathrm{ZnO}$ circular target with a diameter 2 inches with $99.99 \%$ purity from Mercks Chemicals has been used and optimized sputter parameters employed are summarized in Table 2. The surface morphological and crystallographic analysis has been done for the grown graphene and $\mathrm{ZnO}$ layers using SEM (Nova Nano FE-SEM 450) and XRD [18 kW X'Pert Pro Cu-X Ray Diffractometer with $\mathrm{Cu} \mathrm{K} \alpha$ radiation wavelength of $1.542 \AA]$. The electrical characterization of synthesized heterojunction was done using semiconductor device analyzer Agilent B-1500A. 365-nm UV lamp PVU365 from ORANGE, India was used to investigate the UV detection capabilities. The electrical connections as seen from the top side of the device are shown in Fig. 2a and b.

\section{Results and discussion}

The resultant device quality and characteristics are discussed in this section. The surface morphological analysis presents the quality of the grown layers and the device quality can be judged from the device's electrical and UV detection characteristics.

\subsection{Surface morphology analysis}

Figure 1c and d depict the SEM micrographs of the deposited $\mathrm{ZnO}$ and graphene films, respectively. This analysis ensures the crack-free nature of the layer formed along with the high quality of deposition. It is clear from the SEM analysis that the ZnOs are uniformly distributed and good adhesion is showcased. 
Table 1 CVD parameters for graphene growth

\begin{tabular}{lrll}
\hline Gases & Flow rates $(\mathrm{sccm})$ & Deposition phase & Temperature in the chamber \\
\hline $\mathrm{Ar}$ & 100 & Pre deposition & Ramp up from 0 to $1000{ }^{\circ} \mathrm{C}$ \\
$\mathrm{H}_{2}$ & 50 & Deposition & $1000{ }^{\circ} \mathrm{C}$ \\
$\mathrm{CH}_{4}$ & 50 & & \\
$\mathrm{Ar}$ & 50 & Post deposition & Ramp down from 1000 to $0{ }^{\circ} \mathrm{C}$ \\
$\mathrm{H}_{2}$ & 100 & & \\
$\mathrm{Ar}$ & 100 & & \\
$\mathrm{H}_{2}$ & 50 & &
\end{tabular}

Table 2 Sputtering parameters

\begin{tabular}{ll}
\hline Parameters & Values \\
\hline Sputtering power & $100 \mathrm{~W}$ \\
Deposition pressure & 4 to $6 \mu \mathrm{bar}$ \\
Deposition rate & 0.2 to $0.4 \AA \mathrm{s}^{-1}$ \\
Deposition thickness & $100 \mathrm{~nm}$ \\
Ambient used & $\mathrm{Ar}$ \\
Gas flow rate & $10 \mathrm{sccm}$ \\
\hline
\end{tabular}

The grain size for $\mathrm{ZnO}$ is found to be in the range of 50-95 $\mathrm{nm}$. In the micrograph for graphene, uniformity is found in limited areas. Crack free areas in graphene layer is ensured using SEM micrographs and these areas with uniformity and proper adhesion are selectively chosen for further processing.

\subsubsection{AFM}

The AFM images of both graphene and $\mathrm{ZnO}$ films as shown in Fig. 3a-d show that the deposited films are uniform and smooth. The average roughness of the graphene film was found to be $7.59 \mathrm{~nm}$ whereas the $\mathrm{ZnO}$ film depicted an average roughness of $3.35 \mathrm{~nm}$. The 3-D AFM analysis done shows the homogenous distribution of both the films which are seen to be densely grown.

\subsubsection{Crystallography and lattice constants: XRD analysis}

The delaminated graphene layer floating in APS solution with strong back support of PMMA after the copper etching is shown in Fig. 4. This graphene layer gets fished on to PET substrates for further analysis. The results of XRD analysis of the deposited $\mathrm{ZnO}$ film are shown in Fig. 5. The polycrystalline nature of the film is demonstrated by the obtained pattern with (002) dominating among the crystallographic orientations. Using Scherrer formula, the average grain size of the crystals is evaluated and found to be $28 \mathrm{~nm}$ [18]. The lattice parameters $(a, b$, $c)$ are calculated from the obtained diffraction pattern
Fig. 2 Electrical connections using Agilent Semiconductor Analyzer ( 2 probes) for the fabricated heterojunction devices: a $\mathrm{ZnO} / \mathrm{Ag}$ conventional Schottky junction, b Graphene/ZnO Schottky junction (a)

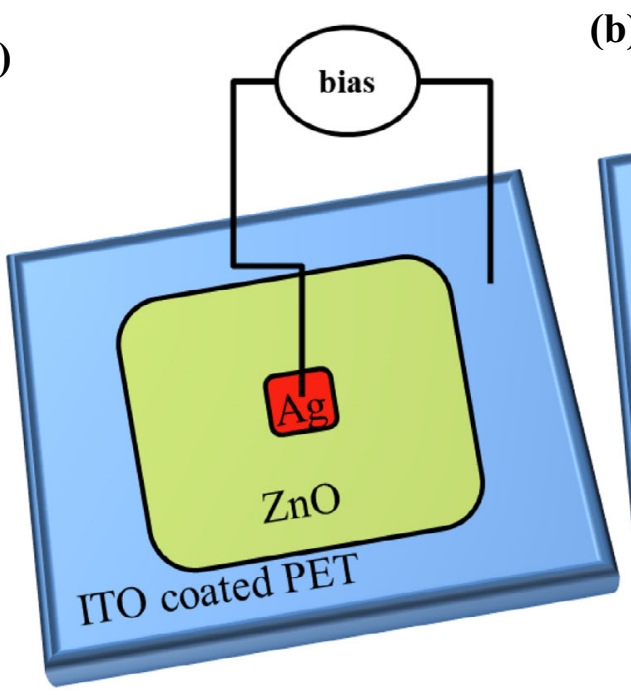

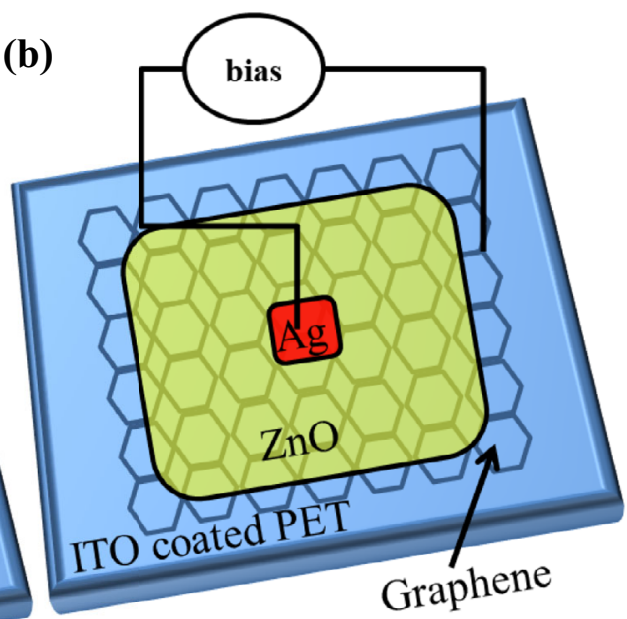


Fig. 3 AFM images of graphene on PET substrate: a 2-D, b 3-D, AFM images of $\mathrm{ZnO}$ on ITO coated PET with graphene layer: c 2-D, d 3-D

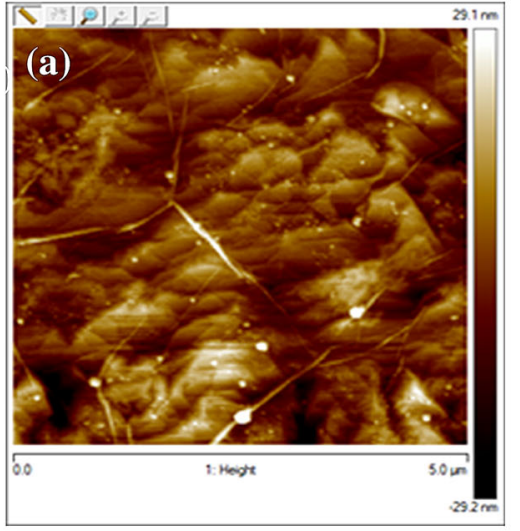

(b)
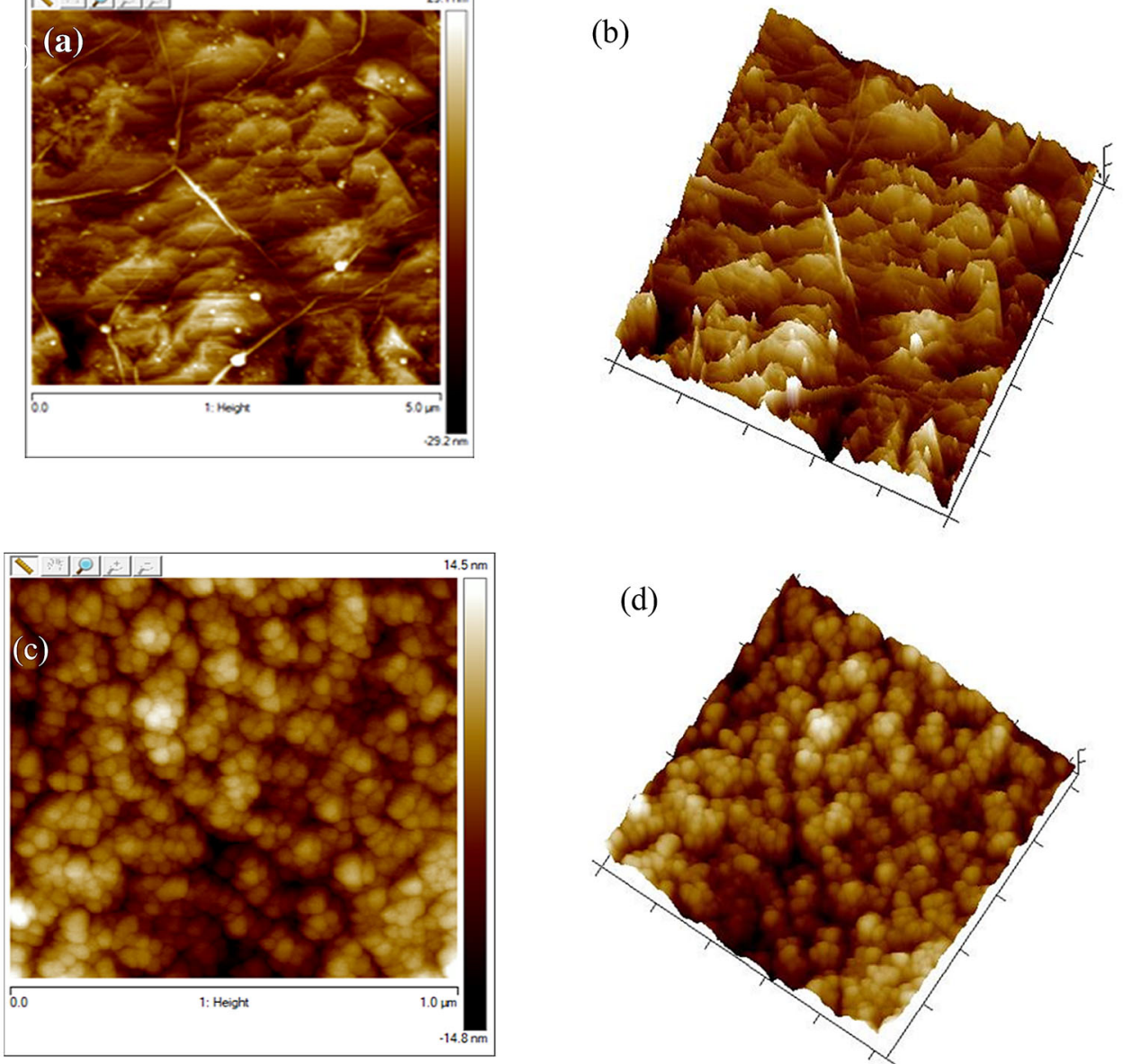

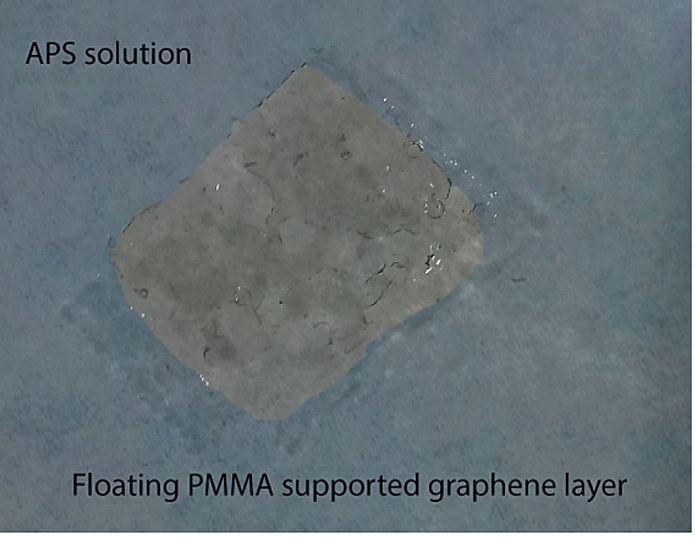

Fig. 4 Delaminated graphene with PMMA floating in APS solution with backside copper etched away

be $a=b=3.02413 \AA$ and $c=5.23796 \AA$ which showed good agreement with standard JCPDS card No. 36-1451 [21].

Dislocation density, strain and stress parameter values were evaluated from XRD data and found to be $1.31270 \times 10^{-3} \mathrm{~nm}^{-2}, 0.25568$ and $-1.43156 \mathrm{GPa}$

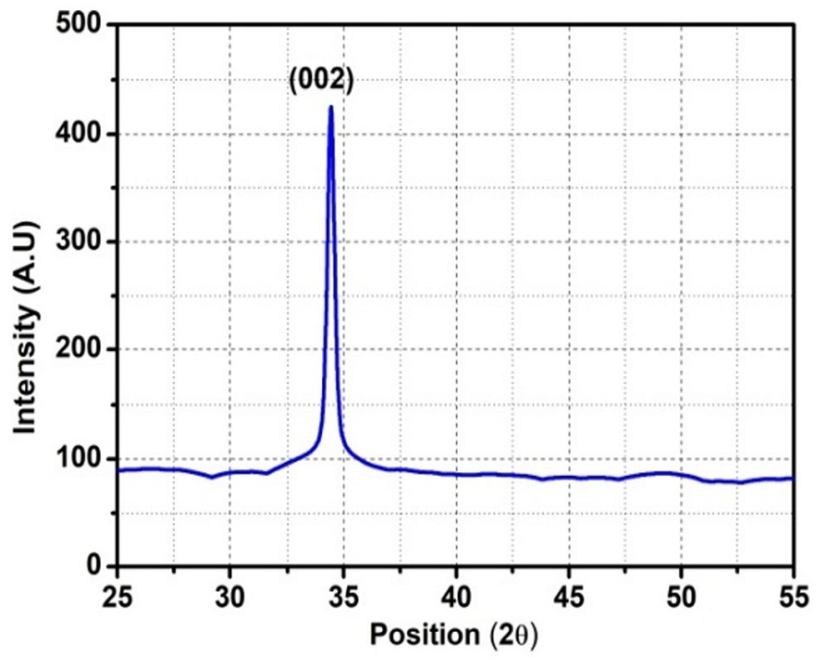

Fig. 5 X-ray diffraction analysis of $\mathrm{ZnO}$ thin film deposited on PET substrate with graphene

respectively. The negative value of stress showed the compressive nature of deposited $\mathrm{ZnO}$ film. 


\subsubsection{Raman spectroscopy}

Raman spectroscopy is the most promising technique for qualitative and quantitative analysis of graphene. Raman spectrum was acquired on STR 500 Confocal Micro Raman Spectrometer (AIRIX Corp. Japan) using $7.5 \mathrm{~mW}$ power of a $532 \mathrm{~nm}$ DPSS laser source for $45 \mathrm{~s}$ of acquisition time. The main peaks appear in Raman spectrum of graphene are D-band, G-band and 2-D band at $1350 \mathrm{~cm}^{-1}, 1580 \mathrm{~cm}^{-1}$ and $2700 \mathrm{~cm}^{-1}$ respectively. The D-band of graphene is associated with the first order of zone boundary phonons, may also be present when defects within the carbon lattice are present. The G-band appears due to the doubly degenerate zone center E2g mode and 2D-band is the second order of zone boundary phonons [22, 23]. Raman spectrum of CVD grown graphene transferred over ITO coated PET substrate is mainly consisted of D-band $\left(1350 \mathrm{~cm}^{-1}\right), \mathrm{G}$-band $\left(1582 \mathrm{~cm}^{-1}\right)$ and 2D-band $\left(\sim 2700 \mathrm{~cm}^{-1}\right)$ (Fig. 6). The smaller D-band intensity compared to G-band indicates good quality of carbon lattice with a smaller number of defects. The $I_{2 \mathrm{D}} / I_{\mathrm{G}}$ ratio for the graphene pattern was found to be $\approx 0.7$ which corresponds to a smaller number of graphene layers [24].

The elemental analysis of the deposited $\mathrm{ZnO}$ thin film has been accomplished by using EDX analysis. PET/glass dummy samples were introduced and $\mathrm{ZnO}$ deposition was done for XRD and SEM analysis of the deposited thin film. The EDX equipment used in this work is BRUKER X-FLASH 6130. The obtained EDX is shown in Fig. 7, this analysis confirms that no contaminants are deposited and only $\mathrm{Zn}$ and $\mathrm{O}$ are

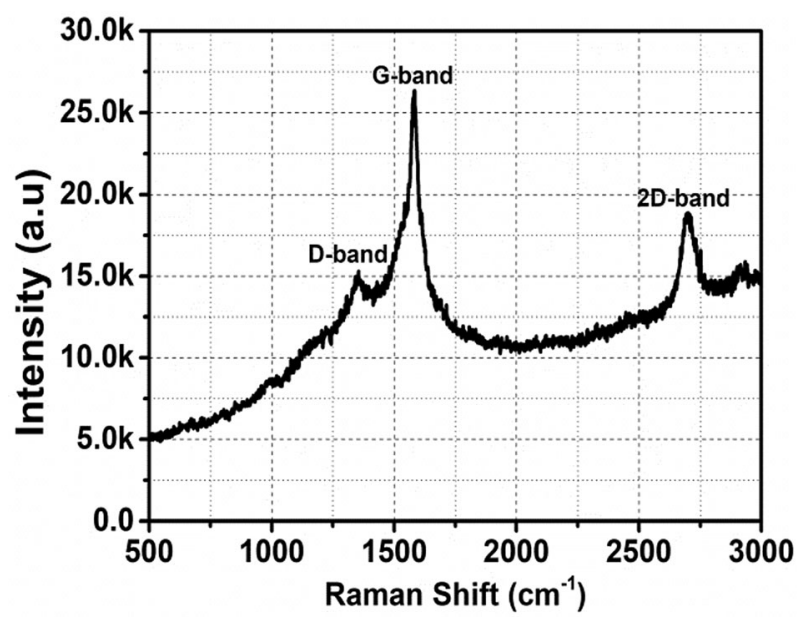

Fig. 6 Raman characteristics of transferred graphene on PET substrate

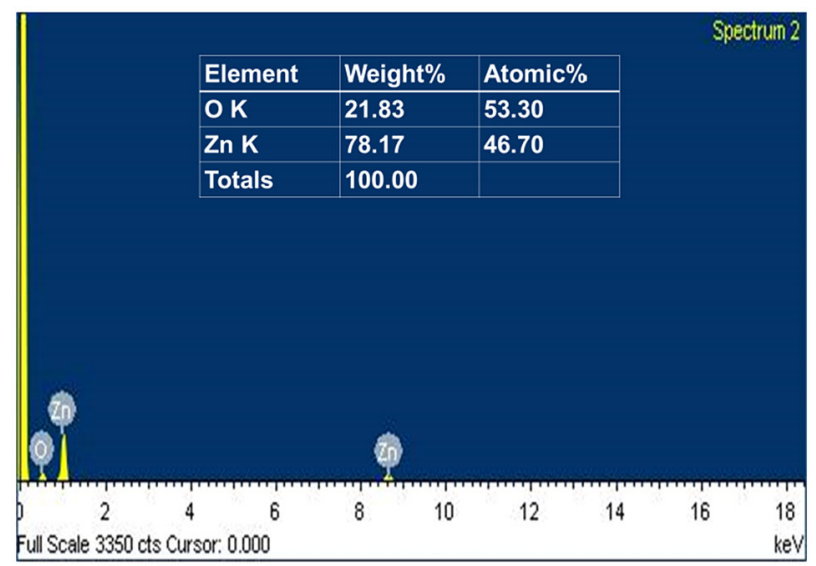

Fig. 7 EDX pattern of deposited $\mathrm{ZnO}$ film on graphene/PET substrate

present in the deposited film. The EDX analysis also proves that no metal contamination has occurred in the device during the sputtering process flow.

\subsubsection{EDS: elemental analysis}

\subsubsection{Electrical $I-V$ characterization}

The electrical $I-V$ characterization of the fabricated $\mathrm{ZnO} /$ graphene heterojunction in both forward and reverse bias is shown in Fig. 8. Ohmic nature of PET/ $\mathrm{ZnO} / \mathrm{Ag}$ contacts was also confirmed, and both the device characteristics are plotted and compared in Fig. $8 \mathrm{a}$ and $\mathrm{b}$. The measurement set up for the same with the device under test (DUT) loaded on the Agilent Parameter Analyzer is shown in Fig. 9. The device operation can be explained by dividing the device characteristics into three sections in the forward bias. First region is where the device exhibits a linear increase in output current. This behavior of the device can be attributed to the tunneling current that dominates the device output. Region 2 is where an exponential increase is seen in the output current. This is due to the increase in tunneling due to recombination that becomes dominant [25]. In the final region when the bias voltage further increases the device, characteristics deviate from the ideal thermionic emission. This variation in characteristics can be attributed to the current conduction in the device that is limited to the space charge, which is the normal behavior in wide bandgap materials [26]. The current transport mechanism in the heterojunction 
Fig. 8 a Linear $I-$

$V$ Characteristics, $\mathbf{b} \log I-$

$V$ Characteristics
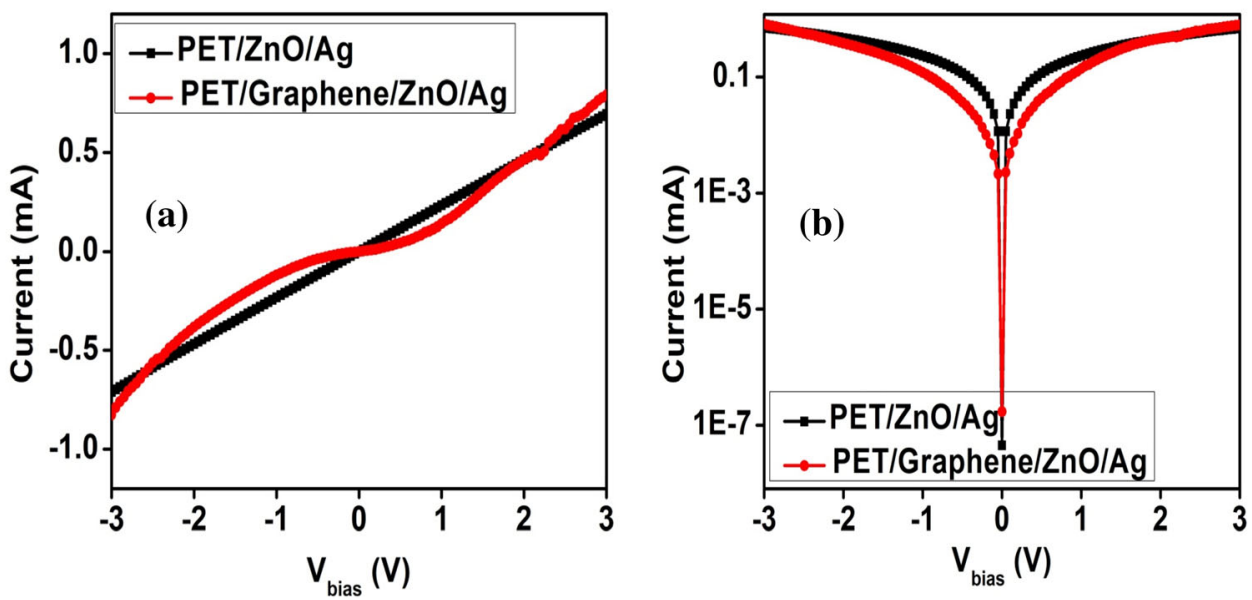

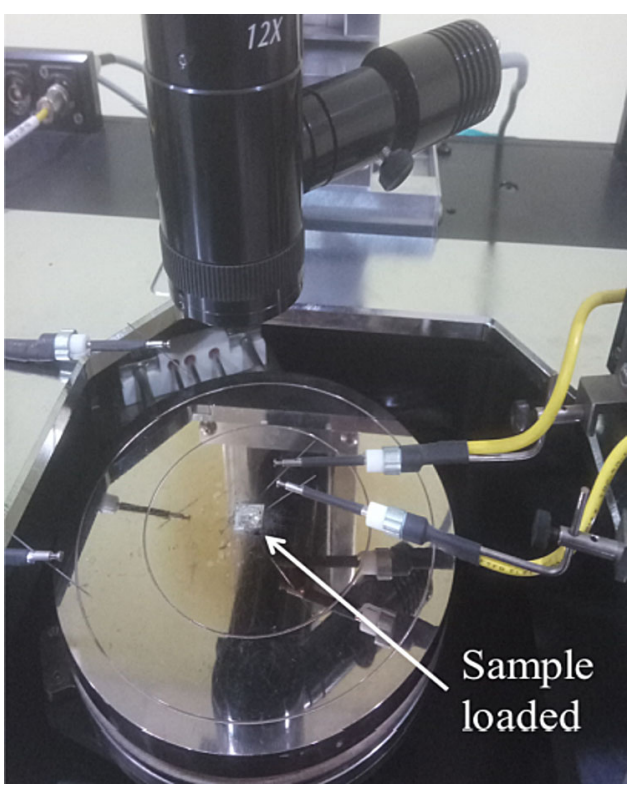

Fig. 9 Device under test (DUT) loaded on the Agilent Parameter Analyzer for electrical characterization

diode due to thermionic emission can be explained using the basic equation:

$I=I_{0} e^{q \mathrm{~V} / \eta \mathrm{kT}}-1$

where $I_{0}$ is the saturation current in the reverse bias, $\mathrm{q}$ is the electron charge, $\eta$ is the ideality factor, $k$ and $T$ are the Boltzmann constant and the temperature respectively. The output diode current in the graphene-modified $\mathrm{ZnO}$ based photodiode is found to be $683 \mu \mathrm{A}$. The device thereby exhibits 6 times higher currents than the existing graphene/ $\mathrm{ZnO}$ diodes where $\mathrm{ZnO}$ nanorod arrays are used [27]. This can be attributed to the increased junction area here which directly affects the diode current as per the equation:

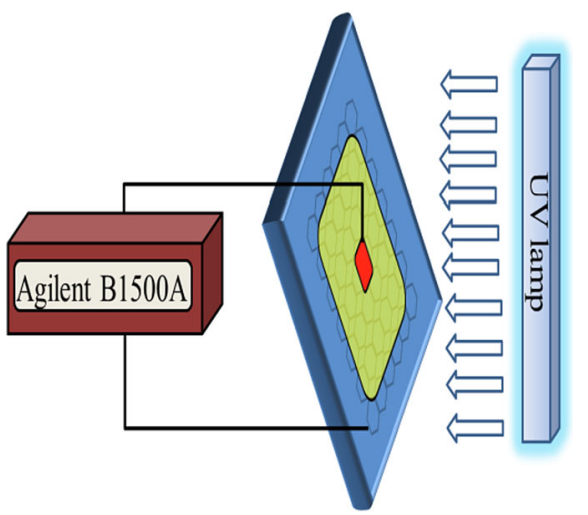

Fig. 10 Schematic representation for UV detection set up

$I=A A^{*} T^{2} e^{-q \Phi_{\mathrm{B}} / \mathrm{kT}} e^{q(V-I R) / n \mathrm{kT}}$

where $\mathrm{a}$ is the area at the heterointerface, $A^{*}$ is Richardson's constant given as

$A^{*}=\frac{4 \pi q m^{* k^{2}}}{\mathrm{~h}^{3}}$

where $\Phi_{\mathrm{B}}$ and $m^{*}$ is the effective barrier height and mass respectively without application of any bias. For $\mathrm{ZnO}, A^{*}$ evaluates to be $32 \mathrm{~A} \mathrm{~cm}^{-2} \mathrm{~K}^{-2}$.

\subsubsection{UV detection}

The schematic of the set up used in UV detection is shown in Fig. 10. On UV exposure, the Schottky barrier in the device is found to disappear virtually as shown in Fig. 11. This result agrees with the reported result Keem et al. [27] which states that when illuminated by UV, the potential barrier at the heterointerface gets lowered. In comparison with the dark current, the illumination current in the reverse bias gets increased by $36 \%$ with light irradiation. 
Vacuum level

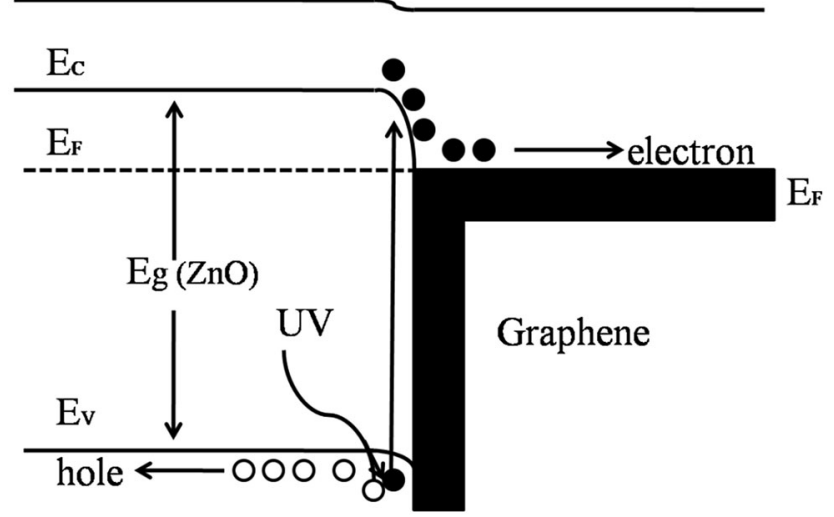

Fig. 11 Energy band diagram of Graphene/ZnO interface under UV illumination

Figure 12 shows the $\log I-V$ characteristics variation from dark current with UV irradiation. The device performance excellence can be attributed to the light trapping effects in the device. Further, the device exhibits fast response and exhibits long term repeatability. The high contrast ratio found in the device may be attributed to the surface hole trap states that are oxygen assisted. These traps prevent the recombination of charge carriers which leads to an increased lifetime of these carriers. Large surface by volume ratio along with the presence of deep surface level trap states increases the carrier lifetimes [10]. This long lifetime and short transit time of the charge carriers can be held responsible for the high sensitivity of the developed photodiode. This ensures the capability of these devices to be used in UV sensing applications. This model for UV detection follows the principles in the previous works [28-30].
The setup for UV and electrical characterization of the device with the device mounted on Agilent Parameter analyzer is shown in Fig. 9 is covered with a thick black cloth for plotting the dark current characteristics, a UV lamp is then introduced to the set up as shown in Fig. 10 for plotting the illumination characteristics. As the $\mathrm{ZnO}$ thin film comes in contact with the oxygen present in the atmosphere, they get adsorbed on the surface through free electron capture in the conduction band of $\mathrm{ZnO}$. The mechanism of UV detection is depicted through the energy band diagram for the graphene/ $\mathrm{ZnO}$ interface under UV illumination condition shown in Fig. 10. The resultant dark current and illumination currents in linear and log scales are plotted in Fig. 12a and b. The process of adsorption in the dark condition can be written as:

$\mathrm{O}_{2}$ (gas) $+e^{-}=\mathrm{O}_{2}^{-}$(adsorbed)

This adsorption results in the formation of a depletion region over $\mathrm{ZnO}$ leading to reduced $\mathrm{ZnO}$ conductivity. On UV exposure, the adsorbed photons lead to the formation of electron-hole pairs.

$h \gamma=h^{+}+e^{-}$

where $\mathrm{h}^{+}$and $\mathrm{e}^{-}$are the holes and electrons generated. These holes that are photogenerated move towards the surface due to the electric field in the depletion region and neutralizes the adsorbed oxygen leading to desorption near the surface. The effective reaction here can be expressed as:

$\mathrm{O}_{2}^{-}$(adsorbed) $+\mathrm{h}^{+}=\mathrm{O}_{2}$ (gas)
Fig. 12 a Dark and illumination currents in linear scale, b Log $I-$

$V$ characteristics for dark and illumination currents
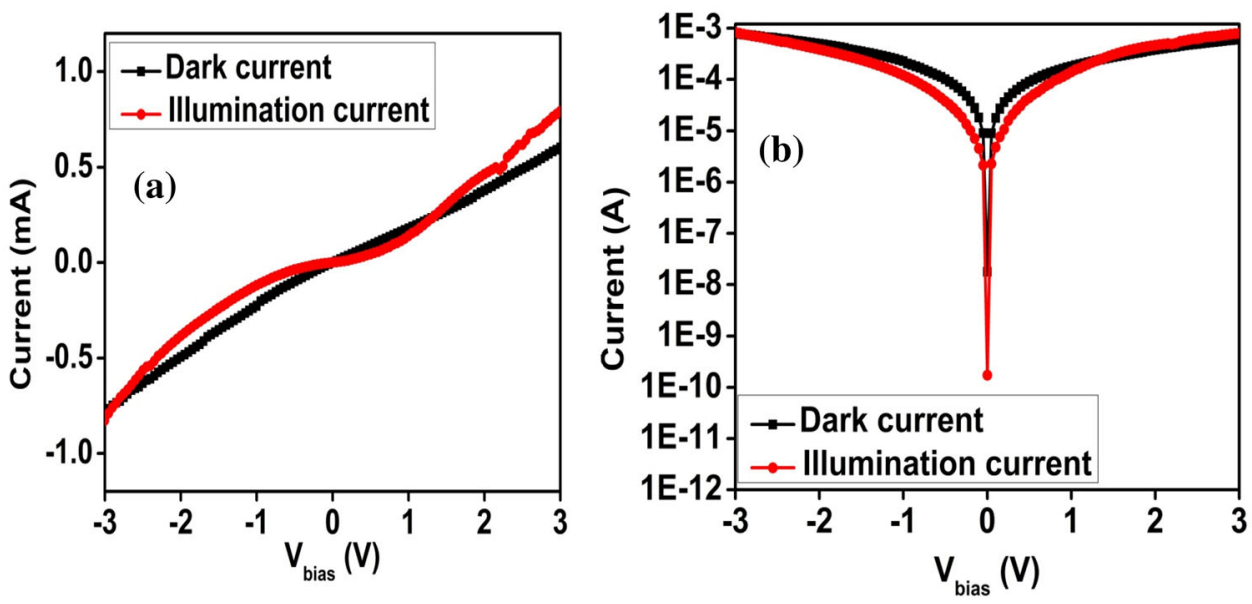
Table 3 Comparison of device performance with existing devices

\begin{tabular}{lll}
\hline Quantity & Responsivity $\left(\mathrm{A} \mathrm{W}^{-1}\right)$ & Detectivity $\left(\mathrm{mH}^{1 / 2} \mathrm{~W}^{-1}\right)$ \\
\hline This work & 0.49 & $7.106 \times 10^{9}$ \\
$\mathrm{Si} / \mathrm{ZnO}$ p-n junction [14] & 0.35 & $4.19 \times 10^{9}$ \\
$\mathrm{Si} / \mathrm{ZnO}$ p-n junction [34] & 0.075 & $6.44 \times 10^{9}$ \\
ZnO Schottky junction [35] & 0.17 & - \\
ZnO Schottky junction [36] & 0.21 & $1.45 \times 10^{9}$ \\
ZnO Metal-semiconductor-metal junction [10] & 0.056 & $1.28 \times 10^{9}$ \\
\hline
\end{tabular}

As desorption is the reverse of adsorption, this increases the concentration of electrons in the conduction band increases leading to increased photo conductance of the device. Further, the oxygen desorption from the surface also increases the conductivity in the device under UV illumination. These trapping processes involved in desorption and adsorption of oxygen atoms make the $\mathrm{ZnO}$ based photodiode a potential candidate in UV detection applications. The responsivity of the device can be evaluated using the expression:

$R=\frac{I_{\mathrm{P}(\mathrm{av})}}{P_{\mathrm{i}-\mathrm{opt}}}$,

where, $I_{\mathrm{P}(\text { av })}$ is the available photocurrent and $P_{\mathrm{i}-\text { opt }}$ is the incident optical power. Available photocurrent in a detector denotes the output device current while the detector is exposed to UV light.

The responsivity of the fabricated graphene $/ \mathrm{ZnO}$ based photodetector was found to be $0.49 \mathrm{~A} \mathrm{~W}^{-1}$. The responsivity in the existing devices that are reported recently lies in the range of 0.1 to 0.35 $\mathrm{A} \mathrm{W}^{-1}[14,31-36]$. The enhanced value of responsivity attained in the fabricated device makes it promising towards practical applications where high responsivity becomes mandatory. Further, the detectivity of the device can be evaluated as [30]:

$D=\sqrt{\left(\frac{R_{0} A}{4 \times k T}\right)} \times\left(\frac{Q \lambda q}{h c}\right)$

where $R_{0}$ is the zero bias device resistance obtained from the device current density characteristics, A is the effective device area, $\mathrm{k}$ is the Boltzmann constant, $\mathrm{T}$ is the lattice temperature, $\lambda, q, h$, and $c$ are the incident wavelength (365 $\mathrm{nm}$ in this work), electron charge, Planck's constant, and speed of light. The $Q$ is the quantum efficiency given by the expression:

$Q=R \times \frac{h c}{q \lambda}$
Substituting Eq. (8) in Eq. (7), the detectivity of the device gets simplified as:

$D=\sqrt{\left(\frac{R_{0} A}{4 k T}\right)} \times R$

At zero bias, the device resistance to area product was found to be $3.56 \Omega$. The detectivity of the device computed using Eq. (9) evaluated to $7.106 \times 10^{9}$ $\mathrm{mHz} \mathrm{z}^{1 / 2} \mathrm{~W}^{-1}$. A comparative analysis of the device performance with the existing $\mathrm{ZnO}$-based UV detectors is presented in Table 3 . The responsivity and detectivity of the device are seen to be higher than the exiting graphene/ZnO-based devices as well as other ZnO-based p-n, MSM and Schottky junctions. The device is expected to exhibit similar responses even when it is bent $[37,38]$. It is clear from the results that the fabricated device outperforms the existing devices and thereby becomes a potential competitor for the existing flexible detectors that are expected to dominate the future's Si photonic and optoelectronic market.

\section{Conclusion}

The $\mathrm{ZnO} /$ graphene heterojunction photodetectors have been fabricated using PMMA-assisted transfer of CVD grown graphene and RF sputtering-based $\mathrm{ZnO}$ deposition. The SEM, XRD, AFM, and Raman spectroscopy-based analysis has been carried out for investigation of the surface morphology and structure of the deposited graphene and $\mathrm{ZnO}$ films. The results show the conformal coating of $\mathrm{ZnO}$ and graphene nanofilms over the entire area of the substrate with good homogeneity. The fabricated device exhibits high detectivity and responsivity of $7.106 \times 109$ $\mathrm{mHz}^{1 / 2} \mathrm{~W}^{-1}$ and $0.49 \mathrm{~A} \mathrm{~W}^{-1}$ respectively. The electrical and UV characterization proves the potential of the device to be used in UV detection applications. 


\section{Author contributions}

Author 1, AK has done the fabrication of the devices while author 2, AV has been involved in characterizations and compiling of the manuscript. Author 3, VJ has helped in experiments, and improving the overall quality of the manuscript.

\section{Funding}

The author, Mr. Ashish Kumar acknowledges the support from Visvesvaraya $\mathrm{PhD}$ Scheme for Electronics and IT/ITes of Ministry of Electronics \& IT, Government of India (Grant No. 1000110042).

\section{Code availability}

All data available.

\section{Declarations}

Conflict of interest The authors declare that they have no conflict of interest.

Open Access This article is licensed under a Creative Commons Attribution 4.0 International License, which permits use, sharing, adaptation, distribution and reproduction in any medium or format, as long as you give appropriate credit to the original author(s) and the source, provide a link to the Creative Commons licence, and indicate if changes were made. The images or other third party material in this article are included in the article's Creative Commons licence, unless indicated otherwise in a credit line to the material. If material is not included in the article's Creative Commons licence and your intended use is not permitted by statutory regulation or exceeds the permitted use, you will need to obtain permission directly from the copyright holder. To view a copy of this licence, visit http://creativecommons.org/licen ses/by/4.0/.

\section{References}

1. J. Chen, W. Ouyang, W. Yang, J.H. He, X. Fang, Recent progress of heterojunction ultraviolet photodetectors: materials, integrations and applications. Adv. Funct. Mater. 30, 1909909 (2020)
2. C. Xie et al., Recent progress in solar-blind deep-ultraviolet photodetectors based on inorganic ultrawide bandgap semiconductors. Adv. Funct. Mater. 29, 1806006 (2019)

3. J.Y. Tsao et al., Ultrawide-bandgap semiconductors: research opportunities and challenges. Adv. Electron. Mater. 4, 1600501 (2018)

4. T. He et al., Broadband ultraviolet photodetector based on vertical $\mathrm{Ga}_{2} \mathrm{O}_{3} / \mathrm{GaN}$ nanowire array with high responsivity. Adv. Opt. Mater. 7, 1801563 (2019)

5. Y. Zou, Y. Zhang, Y. Hu, H. Gu, Ultraviolet detectors based on wide bandgap semiconductor nanowire: a review. Sensors 18, 2072 (2018)

6. L. Su, W. Yang, J. Cai, H. Chen, X. Fang, Self-powered ultraviolet photodetectors driven by built-in electric field. Small 13, 1701687 (2017)

7. A.K. Sharma, S. Yadav, S. Sharma, R. Sharma, IEEE Trans. Nanotechnol. 18, 494 (2019)

8. M. Yasir, S. Bistarelli, A. Cataldo, M. Bozzi, L. Perregrini, S. Bellucci, IEEE Microw. Wirel. Compon. Lett. 29, 47 (2018)

9. B.M. Ataev, A.M. Bagamadova, A.M. Djabrailov, V.V. Mamedov, R.A. Rabadanov, Thin Solid Films 260, 19 (1995)

10. H. Kim, A.C.M. Gilmore, A. Pique, J.S. Horwitz, H. Mattoussi, H. Murata, Z.H. Kafafi, D.B. Chrisey, J. Appl. Phys. 86, 6451 (1999)

11. L. Li, H. Jiang, X. Han, Z. Zhan, H. Du, W. Lu, Z. Li, Z. Tao, Y. Fan, Ceram. Int. 43, 15978 (2017)

12. N.H. Ha, D.D. Thinh, N.T. Huong, N.H. Phuong, P.D. Thach, H.S. Hong, Appl. Surf. Sci. 434, 1048 (2018)

13. T.G.U. Ghobadi, M. Kunduraci, E. Yilmaz, J. Alloys Compd. 730, 96 (2018)

14. G. Zamiri, S. Bagheri, J. Colloid Interface Sci. 511, 318 (2018)

15. P.H. Chen, Y.C. Tsao, Y.C. Chien, H.C. Chiang, H.M. Chen, Y.H. Lu, C.C. Shih, M.C. Tai, G.F. Chen, Y.L. Tsai, H.C. Huang, Adv. Mater. Technol. 4, 8 (2019)

16. M. Khaouani, A. Hamdoune, H. Bencherif, Z. Kourdi, L. Dehimi, Optik 217, 164797 (2020)

17. Y. Liu, L. Du, G. Liang, W. Mu, Z. Jia, M. Xu, Q. Xin, X. Tao, A. Song, IEEE Electron Device Lett. 39, 11 (2018)

18. S. Sharma, B.C. Bayer, V. Skakalova, G. Singh, C. Periasamy, IEEE Trans. Electron. Devices 63, 1949 (2016)

19. T. Ortiz, C. Conde, T.M. Khan, B. Hussain, Appl. Phys. A 123(4), 280 (2017)

20. K.B. Sundaram, A.J.T.S.F. Khan, Thin Solid Films 295(1-2), 87-91 (1997)

21. A. Kumar, M. Prasad, V. Janyani, R.P. Yadav, J. Electron. Mater. 48(9), 5693-5701 (2019)

22. S. Yadav, I. Kaur, Mater. Res. Express 3, 125011 (2016)

23. S. Yadav, V. Kumar, S. Arora, S. Singh, D. Bhatnagar, I. Kaur, Thin Solid Films 595, 193 (2015) 
24. S. Yadav, I. Kaur, RSC Adv. 6, 78702 (2016)

25. R. Ghosh, D. Basak, Appl. Phys. Lett. 90, 243106 (2007)

26. S. Ranwa, P. Kumar Kulriya, V. Dixit, M. Kumar, J. Appl. Phys. 115, 233706 (2014)

27. K. Keem, H. Kim, G.-T. Kim, J.S. Lee, B. Min, K. Cho, M.Y. Sung, S. Kim, Appl. Phys. Lett. 84, 4376 (2004)

28. D.H. Zhang, Mater. Chem. Phys. 45, 248 (1996)

29. S. Lany, A. Zunger, Phys. Rev. B 72, 35215 (2005)

30. I. Beinik, M. Kratzer, A. Wachauer, L. Wang, Y.P. Piryatinski, G. Brauer, X.Y. Chen, Y.F. Hsu, A.B. Djurišić, C. Teichert, Beilstein J. Nanotechnol. 4, 208 (2013)

31. Ü. Özgür, Y.I. Alivov, C. Liu, A. Teke, M. Reshchikov, S. Doğan, V. Avrutin, S.-J. Cho, H. Morkoç, J. Appl. Phys. 98, $11(2005)$

32. Y. Jin, J. Wang, B. Sun, J.C. Blakesley, N.C. Greenham, Nano Lett. 8, 1649 (2008)

33. C. Soci, A. Zhang, B. Xiang, S.A. Dayeh, D.P.R. Aplin, J. Park, X.Y. Bao, Y.-H. Lo, D. Wang, Nano Lett. 7, 1003 (2007)
34. Y.-K. Su, S.M. Peng, L.W. Ji, C.Z. Wu, W.B. Cheng, C.H. Liu, Langmuir 26, 603 (2010)

35. P. Hazra, S.K. Singh, S. Jit, J. Semicond. Technol. Sci. 14, 117 (2014)

36. G.M. Ali, P. Chakrabarti, J. Vac. Sci. Technol. B, Nanotechnol. Microelectron. Mater. Process. Meas. Phenom. 30, 31206 (2012)

37. K.B. Ko, B.D. Ryu, M. Han, C.H. Hong, D.A. Dinh, T.V. Cuong, Appl. Surf. Sci. 481, 524-530 (2019)

38. S.J. Young, Y.H. Liu, M.N.I. Shiblee, K. Ahmed, L.T. Lai, L. Nagahara, T. Thundat, T. Yoshida, S. Arya, H. Furukawa, A. Khosla, ACS Appl. Electron. Mater. 2(11), 3522-3529 (2020)

Publisher's Note Springer Nature remains neutral with regard to jurisdictional claims in published maps and institutional affiliations. 